\title{
Pulmonary Tuberculosis with Hematogenous Spread Associated with Hemaphagocytic Syndrome and Multiple Pulmonary Pneumatoceles
}

Aranda-Cazón Cristina ${ }^{1 *}$, Daoud-Pérez Josefina Zarife ${ }^{1}$, Aleo-Luján Esther ${ }^{2}$, Joyanes Abacens Belén², Francisco-González Laura ${ }^{1}$ and Ramos-Amador José Tomás ${ }^{3}$

${ }^{1}$ Pediatrics Service, Hospital Clinico San Carlos, Calle del Profesor Martin Lagos S/N 28040 Madrid, Spain.

${ }^{2}$ Pediatric Intensive Care Unit, Hospital Clínico San Carlos, Calle del Profesor Martín Lagos, s/n, 28040 Madrid, Spain.

${ }^{3}$ Head of Pediatrics Service, Hospital Universitario Clínico San Carlos, Departamento de Pediatria, Madrid,

Spain; Universidad Complutense. Instituto de Investigación Sanitaria del Hospital Clínico San Carlos (IdISSC).

*Corresponding author: Cristina Aranda Cazón, Pediatrics Service, Hospital Clinico San Carlos, Calle del Profesor Martin Lagos S/N 28040 Madrid Spain, E-mail: aranda.cristina@hotmail.com

Received date: July 4, 2017; Accepted date: August 3, 2017; Published date: August 7, 2017

Copyright: (c) 2017 Aranda-Cazón C, et al. This is an open-access article distributed under the terms of the Creative Commons Attribution License, which permits unrestricted use, distribution, and reproduction in any medium, provided the original author and source are credited.

\begin{abstract}
Background: The association between tuberculosis, multiple bilateral pulmonary pneumatoceles and secondary hemophagocytic syndrome is uncommon. With this case, we would like to highlight the importance of an early and correct diagnosis of tuberculosis to prevent such complications.

Case presentation: We report the case of a 2 months-old infant diagnosed with pulmonary tuberculosis with hematogenous spread and multiorgan involvement that developed multiple bilateral pulmonary pneumatoceles and secondary hemophagocytic syndrome.

Conclusions: Tuberculosis is an important global health issue, with an increased risk to present disseminated forms in the infant. An adequate epidemiological study of an infected patient is essential to prevent the spread of contacts and establish an early treatment to avoid the occurrence of secondary complications that may be lifethreatening.
\end{abstract}

Keywords: Tuberculosis; Pneumatoceles; Hemophagocytic

\section{Abbreviation:}

BIPAP: Biphasic Positive Airway Pressure; CPAP: Continuous Positive Airway Pressure; CPR: Cardiopulmonary Resuscitation; CT: Computed Tomography; HIV: Human Immunodeficiency Virus; PCR: Protein C Reactive; PCR: Polymerase Chain Reaction; PCT: Procalcitonin; PICU: Pediatric Intensive Care Unit; RSV: Respiratory Sincitial Virus; TB: Tuberculosis.

\section{Introduction}

Tuberculosis (TB) is the most common cause of infection-related death worldwide. In 1993, the World Health Organization (WHO) declared tuberculosis to be a global public health emergency. Although pulmonary tuberculosis is the commonest type of TB in children, extrapulmonary tuberculosis can be present in a wide variety of anatomical sites. The association between tuberculosis, multiple bilateral pulmonary pneumatoceles and secondary hemophagocytic syndrome had been scarcely reported in the literature. We would like to highlight the importance of a correct diagnosis of tuberculosis disease and proper study and tracking contacts of the index case, to avoid microepidemics and these complications.

\section{Case Presentation}

We present a case of a bolivian 2 months-old boy, without relevant antecedents and with a correct vaccination schedule, who was referred to our hospital with a history of fever, cough, vomiting and irritability in the last two weeks.

On examination, the patient presented hypoventilation and bilateral rales in pulmonary auscultation, hepatomegaly $(3 \mathrm{~cm})$ and splenomegaly $(2 \mathrm{~cm})$ and irritability. Laboratory tests showed leukocytosis with neutrophilia (17900 leukocytes, neutrophils 59\%) with increased reactants (PCR $15.10 \mathrm{mg} / \mathrm{dl}$ and PCT $3.34 \mathrm{ng} / \mathrm{ml}$ ), urinalysis (intense pyuria, bacteriuria, negative urine culture), nasopharyngeal RSV and influenza test (negative) and chest radiography with bronchopneumonia (Figure 1). He was admitted to a hospital with a diagnosis of pneumonia and suspected urinary tract infection, beginning empirical antibiotic therapy with intravenous cefotaxime and gentamicin. PCR for common respiratory viruses in nasopharyngeal exudate were negative and serology (epstein-barr virus, HIV, treponema pallidum, mycoplasma pneumoniae and chlamydia pneumoniae) were negative.

A severe clinical deterioration was observed in the next $24 \mathrm{~h}$, with higher fever and an important respiratory distress that required supplemental oxygen therapy. Chest radiography showed bilateral pulmonary infiltrates and consolidation in right lung. A complementary medical history was taken from his mother, revealing a two weeks history of asthenia and anorexia with productive cough. In addition, she referred poor weight gain during the last quarter of her pregnancy and an episode of catarrhal symptoms and chest pain. The mother received broad-spectrum antibiotic treatment, as in a respiratory infection, with apparent remission. Inquiring again about family history, she explained that they both live with eigth more 
Citation: Aranda-Cazón C, Daoud-Pérez ZJ, Aleo-Luján E, Joyanes AB, Francisco-González L, et al. (2017) Pulmonary Tuberculosis with Hematogenous Spread Associated with Hemaphagocytic Syndrome and Multiple Pulmonary Pneumatoceles. Clin Microbiol 6: 290. doi: $10.4172 / 2327-5073.1000290$

Page 2 of 5

people, including one maternal uncle who had been diagnosed of bacilliferous pulmonary tuberculosis sensitive to isoniazid a year before the birth of our patient. Then, the entire family unit was studied, with normal results in their tuberculin tests and chest X-rays with the mother exception: her chest radiography showed an image compatible with miliary tuberculosis with positive smear and left pleural effusion. She was admitted for quadruple antituberculous therapy, subsequently withdrawing ethambutol as soon as sputum sensitivity revealed no resistance. Endometrial biopsy and PCR for M. tuberculosis were negative. The two girls in school age residing in the house were treated with primary prophylaxis for 3 months.

Due to the increasing and progressive respiratory requirements (high flow oxygen therapy to $10 \mathrm{bpm}$ and $\mathrm{FiO}_{2} 40 \%$ ), our patient was transferred to our Pediatric Intensive Care Unit (PICU). With the suspected diagnosis based on family history, a chest computerized tomography was performed, demonstrating bilateral and nodular infiltrates, some of them cavitated, associated to a bilateral pleural effusion predominantly in right base. Hypoechoic liver and spleen nodules were found in the abdominal CT, suggesting a septic emboli, as well as axillary, mediastinal, mesenteric, retroperitoneal and inguinal lymphadenopathy. These finding are consistent with miliary tuberculosis with hematogenous spread (Figure 2). A PPD was requested $(0 \mathrm{~mm})$ and Ziehl-Neelsen test in urine, bacterial and mycobacteria urine culture were negative. Lumbar puncture and serial blood cultures were sterile. Treatment with isoniazid, rifampicin, ethambutol, pyrazinamide and methylprednisolone started when consecutive three days gastric aspirates were obtained. In the first gastric aspirate, acid-alcohol-resistant bacilli sensitive to isoniazid and rifampicin were identified. Therefore, ethambutol was suspended and our patient continued triple therapy with initially favorable evolution. Control lumbar puncture remained sterile and no choroidal tuberculomas were present on funduscopy.
In serial controls, the patient presented bicytopenia (minimum hemoglobin $7.2 \mathrm{~g} / \mathrm{dl}$, requiring blood transfusion, and 28000 platelets without bleeding), hypertriglyceridemia (maximum of $564 \mathrm{mg} / \mathrm{dl}$ ), hyperferritinemia (maximum $600 \mathrm{ng} / \mathrm{dl}$ ) and hypofibrinogenaemia $(<100 \mathrm{mg} / \mathrm{dl})$. Bone marrow aspirate was required and showed a slight increase of histiocytes with haemophagocytosis phenomena in some of them, with sterile culture. Immunological study showed normal population quantity and phenotype of NK cells in peripheral blood, with normal cytotoxic activity and degranulation. These findings were consistent with hemophagocytic syndrome, probably secondary to pulmonary tuberculosis, with hematogenous spread.

Initial methylprednisolone was replaced by dexamethasone for 4 days, presenting favorable analytical and clinical course, without any respiratory support to continue treatment. However, $48 \mathrm{~h}$ later, the patient presented new respiratory progressive deterioration. New chest X-ray and CT revealed multiple bilateral cavitations with pneumatoceles, the biggest one of $4 \mathrm{~cm}$ in maximum diameter in the left upper lobe, and multiple areas of bilateral alveolar consolidation (Figure 3). The patient was readmitted to PICU with progressive rising in respiratory support: high flow oxygen therapy and noninvasive ventilation mode continuous positive airway pressure (CPAP) and biphasic positive airway pressure (BiPAP). Finally, on the $9^{\text {th }}$ day of PICU readmission, intubation and conventional mechanic ventilation was required. After $24 \mathrm{~h}$, the patient presented sudden respiratory worsening with cardiopulmonary arrest. Suspecting pneumatoceles rupture, air drainage tap was performed, escaping abundant air from the right hemithorax and less from the left one. At the end, after CPR maneuvers, the patient finally died. Necropsy was not allowed. Table 1 resumes clinical, radiological and analytic parameters found during the hospital admission.

\begin{tabular}{|c|c|}
\hline Hemophagocytic Syndrome & Our patient \\
\hline Molecular diagnosis compatible & No molecular diagnosis \\
\hline Fever & Fever \\
\hline Splenomegaly & Splenomegaly \\
\hline $\begin{array}{l}\text { Peripheral blood cytopenia in at least } 2 \text { of } 3 \\
\text { series: } \\
\text {-Hemoglobin }<9 \mathrm{~g} / \mathrm{dl} \\
\text {-Platelets }<100 \times 10^{9} / \mathrm{L} \\
\text {-Neutrophils }<1 \times 10^{9} / \mathrm{l}\end{array}$ & $\begin{array}{l}\text { Peripheral blood cytopenia in at least } 2 \text { of } 3 \text { series: } \\
\text {-Minimum hemoglobin } 7.2 \mathrm{~g} / \mathrm{dl} \\
\text {-Thrombocytopenia (minimum } 28000 \text { platelets) }\end{array}$ \\
\hline Hypertriglyceridemia (>265 mg/dl) and hipofibrinogenemia (fibrinogen $<150 \mathrm{mg} / \mathrm{dl}$ ) & $\begin{array}{l}\text { Hypertriglyceridemia (maximum of } 564 \mathrm{mg} / \mathrm{dll} \text { ), hyperferritinemia and } \\
\text { hypofibrinogenaemia (<100 mgdl). }\end{array}$ \\
\hline Haemophagocytosis phenomena in bone narrow, lymphadenopathy or spleen & Haemophagocytosis phenomena in bone narrow \\
\hline $\begin{array}{l}\text { Additional criteria: } \\
\text {-Hyperferritinemia }(>500 \mathrm{ng} / \mathrm{ml} \text { ). } \\
\text {-Cytotoxic activity of natural killer cells decreased or absent } \\
\text {-Elevation of soluble receptor of interleukin } 2>2,400 \mathrm{U} / \mathrm{ml} \text { (not determined in our } \\
\text { patient }\end{array}$ & $\begin{array}{l}\text { Additional criteria: } \\
\text {-NK cells normal population quantity and phenotype with appropriate cytotoxic } \\
\text { activity and degranulation. } \\
\text {-Hyperferritinemia (maxinum } 600 \mathrm{ng} / \mathrm{dl} \text { ). } \\
\text {-sIL-2R not studied. }\end{array}$ \\
\hline
\end{tabular}

Table 1: Clinical, radiological and analytic parameters. 
Citation: Aranda-Cazón C, Daoud-Pérez ZJ, Aleo-Luján E, Joyanes AB, Francisco-González L, et al. (2017) Pulmonary Tuberculosis with Hematogenous Spread Associated with Hemaphagocytic Syndrome and Multiple Pulmonary Pneumatoceles. Clin Microbiol 6: 290. doi: $10.4172 / 2327-5073.1000290$

Page 3 of 5

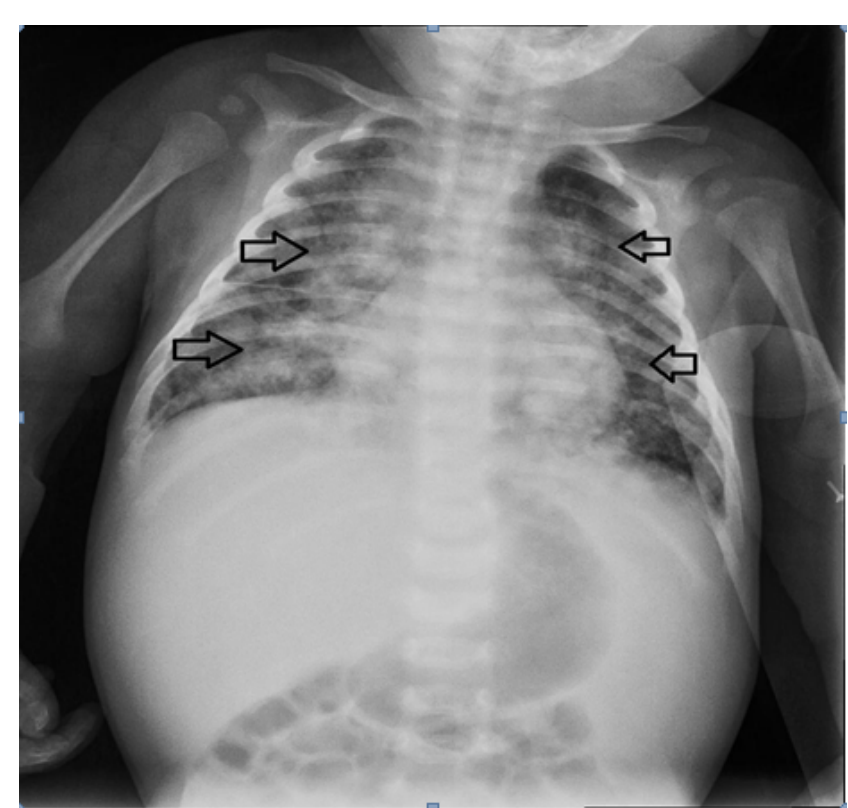

Figure 1: Chest X-ray image showing bilateral alveolar consolidations and bronchogram compatible with bronchopneumonia.

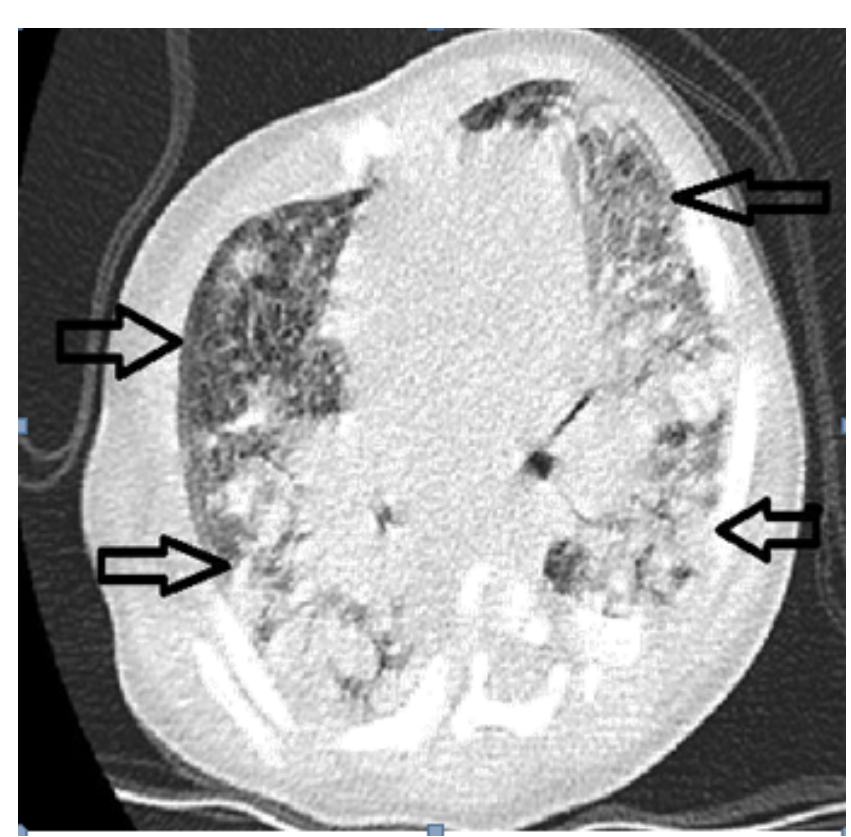

Figure 2: CT image showing bilateral nodular infiltrates, bilateral pleural effusion predominantly in the right base, spleen and liver nodules and axillary, mediastinal, mesenteric, retroperitoneal and inguinal lymphadenopathy.

About the study contact, patient's uncle was interpreted as index case. He voluntarily discontinued treatment within two months and restarted it during admission of our case. Our patient's mother had negative tuberculin test in the study of contacts but she did not receive prophylaxis and she was diagnosed of miliary tuberculosis smearpositive during admission of our case. The mother was probably our patient's source of infection by respiratory route, because congenital tuberculosis was excluded as the patient did not fulfilled Cadtwell 's criterial.

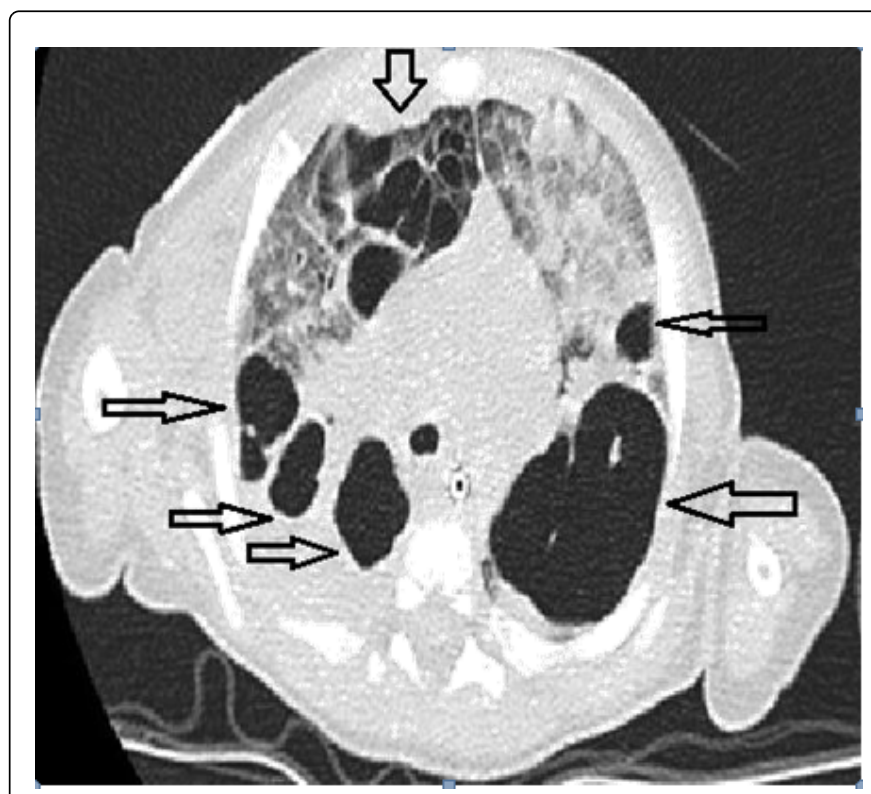

Figure 3: CT image showing multiple pneumatoceles and multiple areas of bilateral alveolar consolidation in the parenchyma not cavitated.

\begin{tabular}{|c|c|}
\hline \multirow{5}{*}{ Initial valoration } & $\begin{array}{l}\text { Fever, caugh, irritability. Bilateral rales in } \\
\text { pulmonary auscultation, hepatomegaly and } \\
\text { splenomegaly. }\end{array}$ \\
\hline & Chest X-Ray: bronchopneumonia. \\
\hline & Urinanalisys: intense pyuria. \\
\hline & $\begin{array}{l}\text { Analitic parameters: leukocytosis with } \\
\text { neutrophilia. }\end{array}$ \\
\hline & Treatment: cefotaxime and gentamicin. \\
\hline \multirow{3}{*}{$24 \mathrm{~h}$ before } & Higher fever and severe respiratory distress. \\
\hline & $\begin{array}{l}\text { Bilateral pulmonary infiltrates and consolidation } \\
\text { in right lung (Figure 1) }\end{array}$ \\
\hline & Mother diagnosis of tuberculosis. \\
\hline \multirow{3}{*}{$\begin{array}{l}\text { Pediatric Intensive Care } \\
\text { Unit }\end{array}$} & $\begin{array}{l}\text { CT: bilateral and nodular infiltrates, some of } \\
\text { them cavitated, bilateral pleural effusion } \\
\text { hypoechoic liver and spleen nodules; and } \\
\text { disseminated lymphadenopathy. }\end{array}$ \\
\hline & $\begin{array}{l}\text { Bicytopenia (hemoglobin } 7.2 \mathrm{~g} / \mathrm{dl} ; \quad 28000 \\
\text { platelets), hypertriglyceridemia }(564 \mathrm{mg} / \mathrm{dl}) \text {, } \\
\text { hyperferritinemia } \quad(600 \\
\text { hypofibrinogenaemia }(<100 \mathrm{mg} \mathrm{dl}) .\end{array}$ \\
\hline & $\begin{array}{l}\text { First gastric aspirate: acid-alcohol-resistant } \\
\text { bacilli sensitive to isoniazid and rifampicin. }\end{array}$ \\
\hline
\end{tabular}


Citation: Aranda-Cazón C, Daoud-Pérez ZJ, Aleo-Luján E, Joyanes AB, Francisco-González L, et al. (2017) Pulmonary Tuberculosis with Hematogenous Spread Associated with Hemaphagocytic Syndrome and Multiple Pulmonary Pneumatoceles. Clin Microbiol 6: 290. doi: $10.4172 / 2327-5073.1000290$

Page 4 of 5

\begin{tabular}{|l|l|}
\hline & $\begin{array}{l}\text { Bone marrow aspirate: slight increase of } \\
\text { histiocytes with haemophagocytosis phenomena } \\
\text { in some of them, with sterile culture. }\end{array}$ \\
\hline & $\begin{array}{l}\text { Immunological study: normal CK cells population } \\
\text { quantity and phenotype and normal cytotoxic } \\
\text { activity and degranulation. }\end{array}$ \\
\hline & $\begin{array}{l}\text { Treatment: quadruple therapy and } \\
\text { methylprednisolone initially (ethambutol } \\
\text { suspended and methylprednisolone replaced by } \\
\text { dexamethasone). }\end{array}$ \\
\hline \multirow{2}{*}{ Readmission to ward } & $\begin{array}{l}\text { Clinical deterioration 48 after. Chest X-ray and } \\
\text { CT revealed multiple bilateral cavitations with } \\
\text { pneumatoceles, and multiple areas of bilateral } \\
\text { alveolar consolidation. }\end{array}$ \\
\hline Readmission to PICU & $\begin{array}{l}\text { Progressive clinical deterioration. } \\
\text { Pneumothorax.Cardiopulmonary arrest and } \\
\text { death. }\end{array}$ \\
\hline
\end{tabular}

Table 2: Diagnostic criteria of hemophagocytic syndrome and those observed in our patient.

\section{Discussion}

Tuberculosis is a worldwide problem with high mortality, especially in developing countries. In childhood, risk of spreading and complications that can seriously compromise life is significantly higher [1]. Therefore, a comprehensive epidemiological study is essential in order to achieve an accurate diagnosis, early and correct treatment and to prevent infection of contacts.

Pneumatoceles are usually associated with bacterial pneumonias $(S$. aureus, S. pneumoniae, $H$ influenzae, Klebsiella, E. coli) [2,3], but they have also been described in $P$. jirovecci in HIV-infected patients 4 or caused by chest trauma. The association with TB disease is unusual and has seldom been described [4-9], even more rarely in childhood [10-13]. Pathogenesis of these lesions remains unclear. Pneumatoceles may be formed from caverns whose content has been emptied by TB treatment. Furthermore, they may appear in areas without parenchymal pulmonary involvement. This last mechanism is favored by the appearance of atelectasis and the effect of rise valve collapse.

Chest CT evaluates size, location and wall thickness, relationship with adjacent structures, underlying complications and value indication and type of treatment. In asymptomatic patients and pneumatoceles smaller than $50 \%$ of hemithorax, a conservative approach can be adopted with serial radiological controls. Usually, they resolve spontaneously, although it could be a slow process that lasts long after the resolution of primary process. In our case, we opted for a conservative management and radiological surveillance of pneumatoceles at the beginning, as the patient initially responded to antituberculous treatment and criteria for drainage aspiration or surgical treatment were not applicable in that moment (symptomatic patients or those with unstable situation, or in whom the size is not reduced or increases after starting appropriate treatment for a prolonged period of time, thickened wall, presence of bronchopulmonary fistula, or atelectasis pulmonary) [14].

Hemophagocytic lymphohistiocytosis is a systemic hyperinflammation reaction due to an exaggerated and ineffective immune response triggered by an antigen, leading to hyperactivation of cytotoxic T lymphocytes and NK cells, cytokines hyperproduction and hyperresponsiveness macrophage infiltrating vital issues $[15,16]$.
Initial symptoms can be confused with sepsis or multiple organ failure. For this reason, diagnosis requires a high index of suspicion. It is characterized by persistent fever, hepatosplenomegaly, lymphadenopathy, rash, edema, jaundice, hypoalbuminemia, hyponatremia, altered coagulation and neurological symptoms (irritability, altered level of consciousness). All of these findings were present in our case.

The diagnosis is confirmed by the International Histiocyte Society criteria 16: genetic confirmation (not done in our case) and/or at least 5 of the following criteria: fever, splenomegaly, bicytopenia (hemoglobin $<9 \mathrm{~g} / \mathrm{dl}$, platelet count $<100 \times 10^{9} / \mathrm{L}$ or neutrophils $<1 \times$ $10^{9} / \mathrm{l}$ ), hypertriglyceridemia ( $>265 \mathrm{mg} / \mathrm{dl}$ ) and / or hipofibrinogenemia (fibrinogen $<150 \mathrm{mg} / \mathrm{dl}$ ) and haemophagocytosis phenomena in bone marrow, lymph node or spleen. We could find all criteria present in our patient. Additional criteria are: hyperferritinemia (>500 ng/ml), cytotoxic activity of natural killer cells decreased or absent (although it may be normal in secondary forms, as in our case), and soluble receptor of interleukin 2 elevation $>2,400 \mathrm{U} / \mathrm{ml}$ (not determined in our patient). Table 2, summarizes the diagnostic criteria of hemophagocytic syndrome and those observed in our patient. The association between tuberculosis and hemophagocytic syndrome in children has been scarcely reported in the literature [17-22]. As sometimes the symptoms are non-specific and radiological findings do not help to guide the diagnosis, this entity should be considered in patients with prolonged fever, pancytopenia and splenomegaly.

Congenital tuberculosis is a rare entity [23-29] but it should be discarded in infected neonates or infants. The diagnosis is based on Cantwell criteria, but our patient did not fulfill the criteria. First of all, maternal endometrial biopsy was not compatible. Secondly, $M$. tuberculosis culture was not obtained in the first week of life. Thirdly, his mother had not referred previously contact with a tuberculosis patient. Also, neither our patient or his mother presented suspicious symptoms. Finally, primary liver caseating granuloma complex was not obtained by histopathological study, due to high invasiveness of the process in the context of our patient instability condition. In addition, there was a likely postnatal infection from his mother, who was smearpositive.

\section{Conclusions}

In conclusion, we would like to highlight the presence of hemophagocytic syndrome secondary to disseminated pulmonary tuberculosis as an entity that requires a high index of suspicion and early treatment to avoid poor prognosis. Also, notice the exceptional nature of the evolution to multiple pneumatoceles, even after the initial apparent clinical and radiological patient improvement. In addition, we consider that a correct diagnosis of tuberculosis disease and a proper study and tracking contacts of the index case are of utmost importance in order to avoid microepidemics and prophylactic treatment in contacts, where an appropriate intervention in the epidemiological chain could have prevented the spread of the disease and fatal outcome of our patient.

\section{References}

1. Cadtwell MF, Shehab ZM, Costello AM, Sands L, Green WF, et al. (1994) Briefreport: congenital tuberculosis. N Engl J Med 330: 1051-1054.

2. Imamoglu M, Cay A, Koscu P, Ozdemir O, Cobanoğlu U, et al. (2005) Pneumatoceles in post- pneumonicempyema: an algorithmic approach. J PediatrSurg 40: 1111-1117. 
Citation: Aranda-Cazón C, Daoud-Pérez ZJ, Aleo-Luján E, Joyanes AB, Francisco-González L, et al. (2017) Pulmonary Tuberculosis with Hematogenous Spread Associated with Hemaphagocytic Syndrome and Multiple Pulmonary Pneumatoceles. Clin Microbiol 6: 290. doi: 10.4172/2327-5073.1000290

Page 5 of 5

3. Holland ET, Saulsbury FT (2003) Chronic Pneumocystis carinii Pneumonia Associated With Extensive Pneumatocele Formation in a Child With Human Immunodeficiency Virus Infection. Pediatr Pulmonol 35: 144-146.

4. Kunyoshi V, Cataneo DC, Cataneo AJ (2006) Complicated pneumonias with empyema and/or pneumatocele in children. PediatrSurgInt 22: 186-190.

5. Duttaroy DD, Jagtap J, Bansal U (2006) Tuberculous pulmonary pneumatocele communicating extrathoracically. Thorax 61: 738 .

6. Wan-Hsiu L, Sheng-Hsiang L, Tsu-Tuan W (2009) Pneumatocele formation in adult pulmonary tuberculosis during antituberculous chemotherapy: a case report. Cases J 2: 8570.

7. Duttaroy DD, Jagtap J, Bansal U, Duttaroy B (2006) Tuberculous pulmonary pneumatocele communicating extrathoracically. Thorax 61 : 738.

8. Long R, Maycher B (1998) Check-valve pneumatocele formation following fully treated tuberculosis: case report. Can AssocRadiol J 49: 197.

9. Hong SJ, Hwang S, Hwang SH, Kim DY, Kong SJ (2011) Extrathoracic communication of persistent pulmonary tuberculous pneumatocele. Respiration 81: 247-248.

10. Madden RE, Viswanathan TK, Verghese KP (1968) Solitary pneumatocele in childhood tuberculosis. Ann Thorac Surg 5: 347-351.

11. Kending EL, Choy Jr SH, Johnson WH (1956) Observation on the effect of cortisone in the treatment of tuberculous meningitis. Amer RevTuberc 73: 99-109.

12. Kress MB, Finkelstein AH (1962) Giant bullous emphysema occurring in tuberculosis in childhood. Pediatrics 30: 169.

13. Steiger A (1963) Tuberculous pulmonary emphysema. Rev Chile Pediat 34: 129.

14. Imamoglu M, Cay A, Kosucu P, Ozdemir O, Cobanoğlu U, et al. (2005) Pneumatoceles in postpneumonic empyema: analgorithm icapproach. J PediatrSurg 40: 1111-1117.

15. Martínez PA, Hemofagocíticos SI (2013) concepto, clasificación, fisiopatiología y clínica. An Pediatr Contin 11: 237-244.

16. Henter JI, Horne A, Arico M, Egeler RM, Filipovich AH, et al. (2007) HLH 2004: Diagnostic and therapeutic guidelines for hemophagocytic lymphohistiocytosis. Pediatr Blood Cancer 48: 124.
17. Seoh JH, Lee JA, Kim DH, Cho J, Lim SJ (2016) Tuberculosis-associated hemophagocytic lymphohistiocytosis in adolescent diagnosed by polymerase chain reaction. Korean J Pediatr 59: 43-46.

18. Dey A, Shah I, Pradnya P, Vaishnavi I (2014) Tuberculosis with hemophagocytic lymphohistiocytosis in an infant. Indian J Pediatr 81: 214-215.

19. Balasubramanian S, Kaarthigeyan K, Aparna V, Srinivas S (2008) Tuberculosis-associated haemophagocytic syndrome in infancy. Indian Pediatr 45: 593-595.

20. Gupta AP, Parate SN, Bobhate SK, Anupriya (2009) Hemophagocytic syndrome: a cause for fatal outcome in tuberculosis. Indian J Pathol Microbiol 52: 260-262.

21. Deshpande Al, Nayar PS, Pradhan AM, Manchanda RV (2010) Miliary tuberculosis with hemophagocytosis in a two months old infant. Indian J Hematol Blood Transfus 26: 115-117.

22. Dilber E, Erduran E, Kalyocu M, Aynaci FM, Okten A, et al. (2002) Hemophagocytic syndrome as an initial presentation of miliary tuberculosis without pulmonary findings. Scand J InfectDis 34: 689-692.

23. Artigao BF, Peña MJ, Rabes DRT, Julián AN, Mellgren GA, et al. (2015) Guía de la Sociedad Española de Infectología Pediátrica sobre tuberculosis en la embarazada y en el recién nacido (I): epidemiología y diagnóstico. Tuberculosis congénita. AnPediatr (Barc) 83: 285.e1-288.

24. Rosal TD, Artigao BF, Echevarría MA, Mellado MJ (2016) Unsuspected congenital tuberculosis. Pediatr Infect Dis J 35: 225.

25. Mony VK, Polin J, Adler E, Munjal I, LaTuga MS, et al. (2014) Congenital Tuberculosis: A Missed Opportunity. J Pediatric Infect Dis Soc 3: e45-47.

26. Orrego HA, Hoeneysberg TM, Cuenca DL (2015) Congenital Tuberculosis as a Result of Disseminated Maternal Disease: Case Report. Tuberc Respir Dis (Seoul) 78: 450-454.

27. Raj P, Sarin YK (2014) Congenital tuberculosis in a neonate: a diagnostic dilema. J Neonatal Surg 3: 49.

28. Adhikari M, Pillay T, Pillay DG (1997) Tuberculosis in the newborn: an emerging disease. Pediatr Infect Dis J 16: 1108-1112.

29. Abughali N, Kuyp VDF, Annable W, Kumar ML (1994) Congenital tuberculosis. Pediatr Infect Dis J 13: 738-741. 